\title{
SERUM INTERLEUKIN-6 LEVELS IN MURINE MODELS OF CANDIDA ALBICANS INFECTION
}

\author{
RENÁTÓ KOVÁCS ${ }^{1}$, ANITA CZUDAR ${ }^{1}$, LÁSZLÓ HORVÁTH ${ }^{2}$, \\ LEVENTE SZAKÁCS ${ }^{1}$, LÁSZLÓ MAJOROS $^{1}$ and JÓZSEF KÓNYA ${ }^{1 *}$ \\ ${ }^{1}$ Department of Medical Microbiology, ${ }^{2}$ Central Pharmacy, \\ Faculty of Medicine, University of Debrecen, Debrecen, Hungary
}

(Received: 27 November 2013; accepted: 13 January 2014)

Two Balb/C mouse models of Candida infection were used to detect serum interleukin-6 (IL-6) responses. The first model used systemic infection by Candida albicans ATCC 10231 strain infected through the lateral tail vein of mice without any specific pretreatment. The median Candida burdens of the kidneys were $1.5 \times 106$ $\mathrm{CFU} / \mathrm{ml} 24 \mathrm{~h}$ postinoculation (p.i.) and $1.2 \times 107 \mathrm{CFU} / \mathrm{ml} 72 \mathrm{~h}$ p.i., while median serum IL-6 levels were $479.3 \mathrm{pg} / \mathrm{ml}$ and $934.5 \mathrm{pg} / \mathrm{ml}$, respectively. The Candida burden showed significant correlation with serum IL-6 24 h p.i. $\left(\mathrm{R}^{2}=0.6358 ; \mathrm{P}=0.0082\right)$ but not $72 \mathrm{~h}$ p.i.

The second model was a mouse vaginitis model applying intravaginal inoculation of mice pretreated with subcutaneous estradiol-valerate $(10 \mathrm{mg} / \mathrm{ml}) 3$ days before infection. Candida cell count in vaginal lavage fluid was $2.8 \times 10^{6} \mathrm{CFU} / \mathrm{ml} 24 \mathrm{~h} \mathrm{p}$.i. and $1.4 \times 10^{8} \mathrm{CFU} / \mathrm{ml} 72 \mathrm{~h}$ p.i. Serum IL- 6 response was detected in 4 of 15 mice $24 \mathrm{~h}$ p.i. and 9 of 15 mice $72 \mathrm{~h}$ p.i. Even the responders had low IL-6 serum levels (mean values $29.9 \mathrm{pg} / \mathrm{ml}$ and $60.1 \mathrm{pg} / \mathrm{ml}$, respectively) not correlating with Candida cell count in vaginal lavage fluid.

In conclusion, serum IL-6 had strong relationship with systemic $C$. albicans infection while the local $C$. albicans infection of the vagina led to partial, prolonged and limited serum IL-6 response.

Keywords: interleukin-6, vulvovaginitis, systemic candidiasis, mouse, Candida albicans

\footnotetext{
* Corresponding author; E-mail: konya@med.unideb.hu
} 


\section{Introduction}

Candida albicans (C. albicans) is a permanent member of the human microbiome and colonizes the human gastrointestinal, respiratory and reproductive tracts. However, when the host physiology is damaged (i.e. immunosuppressant therapy, diabetes mellitus) this fungal-host interrelationship can degenerate and may lead to opportunistic fungal infections, which emerge as mucosal or invasive fungal disease $[1,2]$.

Candida species are the fourth most frequent cause of healthcare-associated bloodstream infections in the hospital environment, which is associated with high mortality (30-50\%) [3]. On the basis of the ARTEMIS DISK 1997-2003 surveillance program $C$. albicans is the most common species causing disseminated candidiasis worldwide (66\% of all Candida species) [3, 4]. According to last published epidemiology data, comparable rate was observed at University of Debrecen and at University of Szeged, C. albicans was identified in 58\% and 64\% of Candida-positive blood culture, respectively [5,6]. The major risk factors of Candida-caused bloodstream infections are immunosuppressant therapy, broadspectrum antibacterial agents, prolonged use of catheters in intensive care unit as well as different surgery interventions [4].

Vulvovaginal candidiasis (VVC) is a common mucosal infection caused by different Candida species including C. albicans. Approximately $70-75 \%$ of healthy women suffer at least one VVC episode during their childbearing age. In the USA VVC is the second most common type of vaginal infections after bacterial vaginitis. The most typical predisposing factors of VVC are disturbance in hormone levels owing to pregnancy, antibiotic treatment, high-estrogen contraceptive usage and uncontrolled diabetes mellitus [7, 8].

During the acute phase of infection, IL-6, a $22-30 \mathrm{kDa}$ glycoprotein is secreted into the bloodstream and induces both $\mathrm{B}$ cell and $\mathrm{T}$ cell differentiation as well as production of antibodies and acute phase proteins [9-11]. Since host cytokine response against Candida infection is poorly understood, a systemic and a vaginal candidiasis mouse model were used to measure serum IL-6 responses.

\section{Materials and Methods}

In the course of experiments the strain C. albicans 10231 ATCC was used. Balb/C immunocompetent female mice (19-22 g) were infected in our in vivo models. The animals were maintained in accordance with the Guidelines for the 
Care and Use of Laboratory Animals. The experiments were approved by the Animal Care Committee of the University of Debrecen (permission no.: 12/2008).

During the examination two models were used (vaginal and systemic infection mouse model). Animals were divided into 3 major groups per models. In vaginal infection model, $50 \mu \mathrm{l}$ subcutaneous estradiol-valerate $(10 \mathrm{mg} / \mathrm{ml})$ was given to all mice three days prior to infection [11-13].

Animals were infected intravenously through the lateral tail vein $(200 \mu 1$ of infective inoculum) in case of systemic model [14]. In the systemic model the infectious dose of $C$. albicans was $3 \times 10^{5} \mathrm{CFU} /$ mouse based on our preliminary investigations. In the vaginal model, mice were infected intravaginally with $3 \times 10^{5}$ stationary-phase $C$. albicans cells in $50 \mu 1$ volumes. Inoculum density was confirmed by plating serial dilution on Sabouraud agar plates. In case of systemic mouse model the animals were sacrificed (cervical dislocation) after $24 \mathrm{~h}$ and $72 \mathrm{~h}$, kidney pairs were removed and homogenized aseptically. Fungal tissue burden was determined by quantitative culturing. The homogenates were diluted by $1 \mathrm{ml}$ sterile saline and serial tenfold dilutions were made in saline, subsequently plated onto Sabouraud dextrose agar and the colony count was determined after $48 \mathrm{~h}$. The control mice did not receive infective inoculation [14].

At $24 \mathrm{~h}$ p.i. the first group of the mice of vaginal model was sacrificed and flushed their vagina with sterile physiological saline $(100 \mu \mathrm{l})$. Thereafter $50 \mu \mathrm{l}$ volumes was taken out from lavage fluid, serially diluted tenfold and plated onto Sabouraud dextrose agar. This method was repeated after $72 \mathrm{~h}$ at the second group. The third group (control mice) received just hormone treatment. Control mice were investigated both at $24 \mathrm{~h}$ p.i. and $72 \mathrm{~h}$ p.i. All colony counts were determined after $48 \mathrm{~h}$ culture on Sabouraud plates.

In case of both models, blood was taken in way of retro-orbital with Pasteur pipette ( $0 \mathrm{~h}, 24 \mathrm{~h}$ and $72 \mathrm{~h}$ p.i.). The samples were centrifuged at $24 \mathrm{~h}$ after the collection $(5$ minute $6000 \times \mathrm{g}$ ). The serum was isolated from each sample and put into sterile Eppendorf tubes. The serum samples were stored at $-20^{\circ} \mathrm{C}$.

The serum samples were measured by Luminex XMAP (Biomedica) with mouse cytokine panel. The differences between groups were analyzed by Mann-Whitney U-test. Chi-square for trend test was used to test increasing number of responders by time. The level of significance was set at $\mathrm{P}<0.05$. 


\section{Results}

IL-6 levels and systemic infection

At $24 \mathrm{~h}$ after intravenous C. albicans ATCC 10231 inoculation, the median of cell count was $1.5 \times 10^{6} \mathrm{CFU} / \mathrm{ml}$. The distribution of the Candida burden at $24 \mathrm{~h}$ was characterized by 2 mice with kidneys remained sterile and 13 mice with Candida cell count ranging $6 \times 10^{5}-8.6 \times 10^{6} \mathrm{CFU} / \mathrm{ml}$. An average 7.6-fold increase was found in the infected kidneys compared with the starting inoculums (Fig. 1).
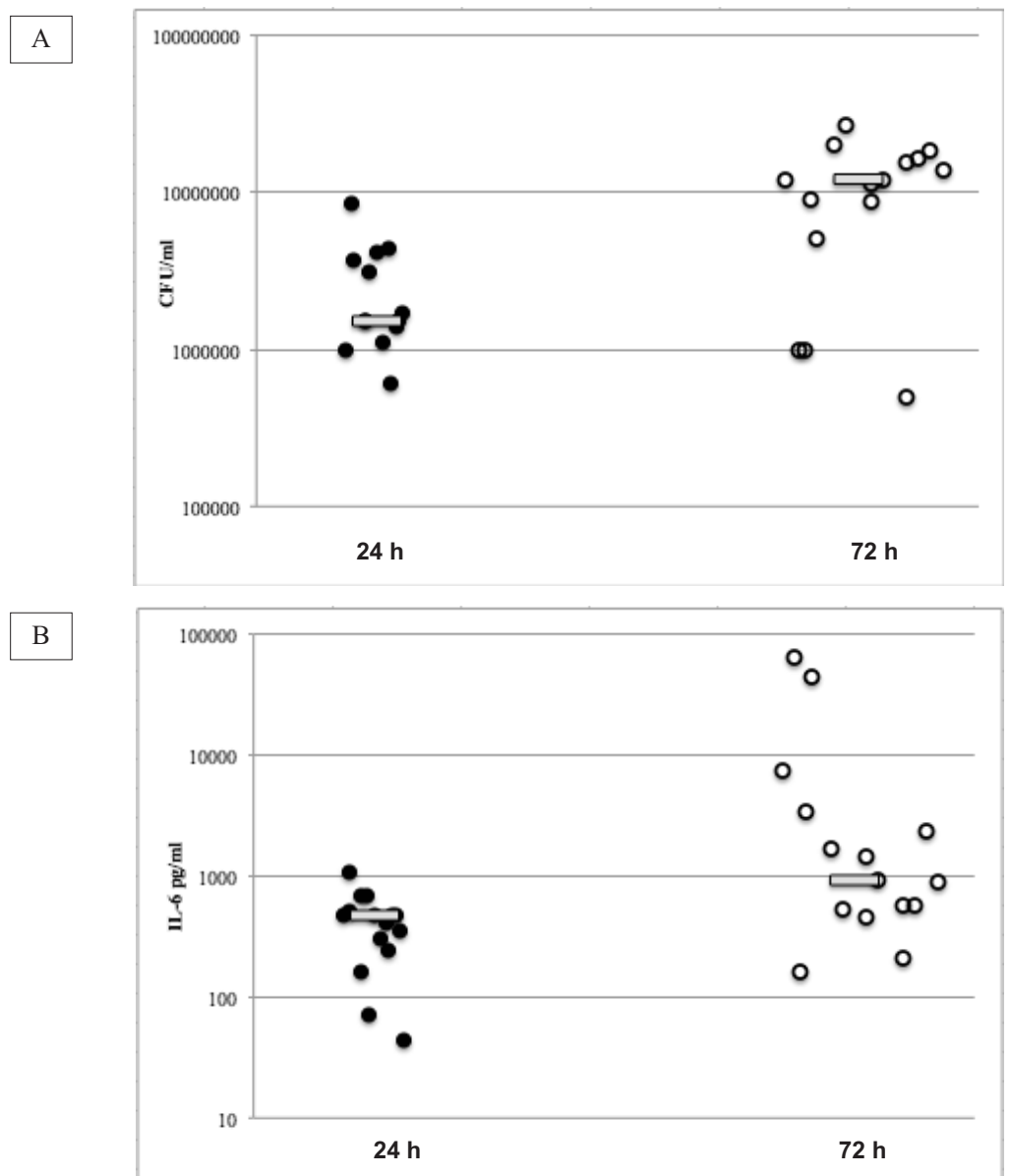

Figure 1. Candida cell burden of mice kidneys (A) and IL-6 levels of serum (B) in systemic candidiasis. At $24 \mathrm{~h}$ the two lowest IL-6 values $(<100 \mathrm{pg} / \mathrm{ml})$ belong to mice with kidneys remained sterile

Acta Microbiologica et Immunologica Hungarica 61, 2014 
At $72 \mathrm{~h}$ after intravenous $C$. albicans ATCC 10231 inoculation, the median of cell count was $1.2 \times 10^{7} \mathrm{CFU} / \mathrm{ml}$. All 15 mice revealed Candida infection in the kidneys, the Candida cell count ranged from $5 \times 10^{5} \mathrm{CFU} / \mathrm{ml}$ to $2.7 \times 10^{7} \mathrm{CFU} / \mathrm{ml}$. An average 38-fold increase was found in the infected kidneys compared with the starting inoculums. The increase in the Candida burden of the kidneys between days 1 and 3 was significant $(\mathrm{P}=0.002)$ (Fig. 1).

On day 0 , the baseline serum IL-6 was below the detection level in all tested mice as well as serum IL-6 levels of control mice remained below detection level after either $24 \mathrm{~h}$ or $72 \mathrm{~h}$ observation. In mice inoculated with C. albicans, the serum IL-6 level were markedly above the detection threshold both $24 \mathrm{~h}$ and $72 \mathrm{~h} \mathrm{p}$.i. (44.2-1083.6 pg/ml at $24 \mathrm{~h} ; 162.4-64841 \mathrm{pg} / \mathrm{ml}$ at $72 \mathrm{~h})$. Nevertheless, the two mice with sterile kidneys at $24 \mathrm{~h}$ p.i. had outlyingly low serum IL-6 levels. Between days 1 and 3, the IL-6 level of the serum had an average 20 -fold increase (P $=0.004)$ (Fig. 1). At $24 \mathrm{~h}$ correlation was observed between the Candida cell count and IL-6 level $\left(\mathrm{R}^{2}=0.6358, \mathrm{P}=0.0082\right)$. After 3 days of the infection, the correlation disappeared in spite of the increasing trend of both markers $\left(R^{2}=0.20747\right)$ (Fig. 2).

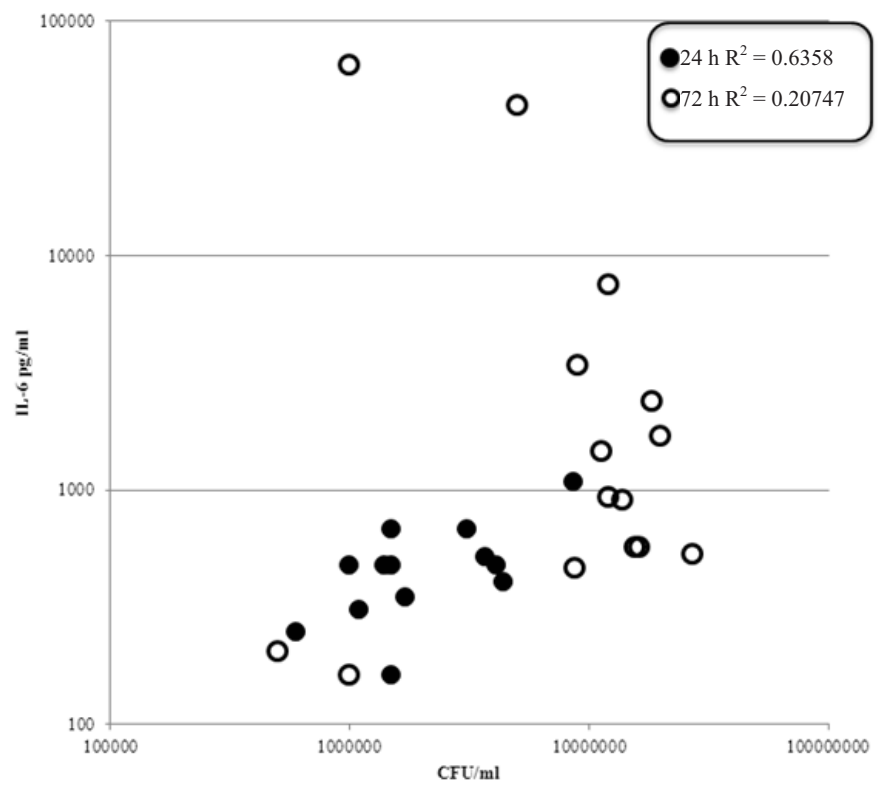

Figure 2. Correlation between Candida cell count (CFU/ml) and IL-6 level (pg/ml) in systemic candidiasis model at $24 \mathrm{~h}$ and $72 \mathrm{~h}$ 


\section{IL-6 levels and vaginal infection}

At $24 \mathrm{~h}$ after intravaginal C. albicans ATCC 10231 inoculation, all 15 mice was suffering from marked vaginal discharge, the median Candida cell count was $2.8 \times 10^{6} \mathrm{CFU} / \mathrm{ml}$ vaginal lavage fluid (range: $1 \times 10^{5}-3 \times 10^{7} \mathrm{CFU} / \mathrm{ml}$ ). An average 19.6-fold increase was detected in the lavage fluid compared with the starting inoculums. At $72 \mathrm{~h}$ after vaginal $C$. albicans inoculation, the median of cell count was $1.4 \times 10^{8} \mathrm{CFU} / \mathrm{ml}$. All 15 mice revealed Candida infection in their vagina, the Candida cell count ranged from $9.4 \times 10^{5} \mathrm{CFU} / \mathrm{ml}$ to $6.5 \times 10^{8} \mathrm{CFU} / \mathrm{ml}$. On day 0 , the baseline serum IL-6 was below the detection level in all tested mice. At $24 \mathrm{~h}$

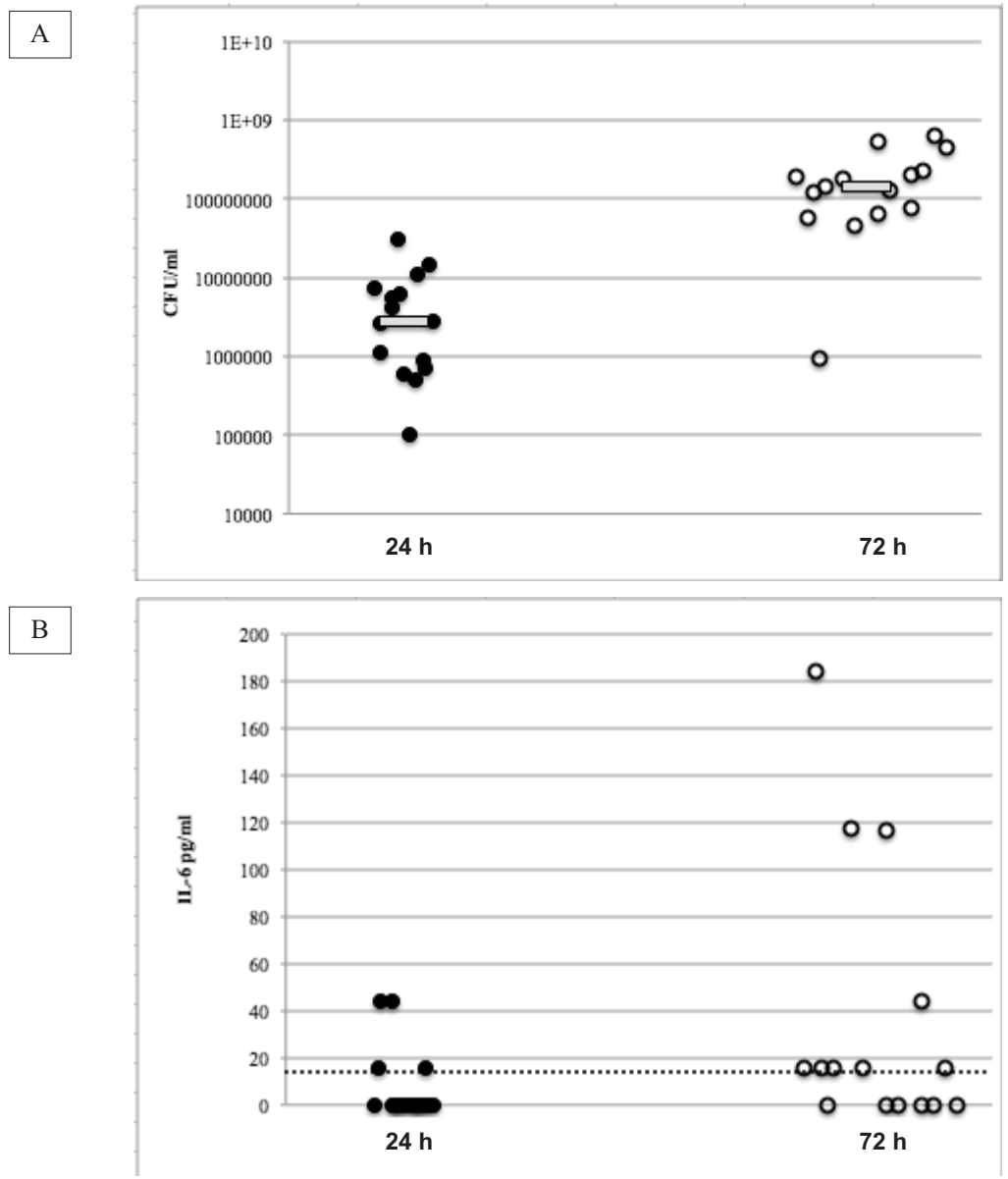

Figure 3. Candida cell burden of lavage fluid (A) and IL-6 levels of serum (B) in vulvovaginal candidiasis

Acta Microbiologica et Immunologica Hungarica 61, 2014 
detectable IL-6 level was observed above the threshold in 4 of 15 mice. At $72 \mathrm{~h}$ this ratio was 9 out of 15 . At $24 \mathrm{~h}$ and $72 \mathrm{~h}$ detectable IL-6 levels were not noticed in control mice. The proportion of IL-6 responder mice significantly increased by time of infection $(\mathrm{P}=0.01)$. The ranges serum IL-6 levels of the responders to vaginal infection ( $15.6-44.2 \mathrm{pg} / \mathrm{ml}$ at $24 \mathrm{~h}$ p.i. and $15.6-184 \mathrm{pg} / \mathrm{ml}$ at $72 \mathrm{~h}$ p.i.) were much lower than the levels measured in systemic infections (Fig. 3).

\section{Discussion}

C. albicans is one of the most common inhabitants of our microbiome. This Candida species caused infections can emerge from mucocutaneous candidiasis to life-threatening candidaemia $[2,3,15]$.

During our investigations proinflammatory IL-6 cytokine response was determined in case of systemic candidiasis and in Candida vaginitis mouse model. In the course of $C$. albicans infection, some proinflammatory cytokines (IL-6, TNF- $\alpha$, IL-12) are essential for the efficient control of infection [7]. IL-6 induces acute phase proteins increased secretion therefore it has a pivotal role for development on proper innate immune response [7]. Romani et al. observed that IL-6 deficient mice are more susceptible to disseminated candidiasis than wild-type mice [16] suggesting that IL-6 production is fundamental in terms of protection [17].

In the background of two mice with sterile kidneys $24 \mathrm{~h}$ after intravenous inoculation of $C$. albicans, we assume the role of time factor, i.e. the systemic infection has not completely resulted in colonization of kidneys by this time in the whole inoculated population. Systemic proliferation of $C$. albicans might have been delayed in these two mice as indicated by serum IL- 6 levels exceeding those in single organ infected but scoring under the IL-6 levels of mice with kidney colonization. In the disseminated candidiasis model at $24 \mathrm{~h}$ the measured IL-6 level correlated with the Candida cell count. By 72 h p.i., the serum IL-6 levels increased further, however lost correlation with microbial burden. An explanation for this phenomenon is that strong defence mechanisms might have interfered with the microbial burden more efficiently by this time. Another possible explanation is that the serum IL-6 levels by this time might be close to the individual maximum value. Steinshamn et al. investigating serum IL-6 level from $3 \mathrm{~h}$ to $72 \mathrm{~h}$ p.i. in their mouse model observed its peak at $24 \mathrm{~h}$ [18]. Comparable IL-6 level was observed at $24 \mathrm{~h}$ in case of our disseminated candidiasis model. However, at $72 \mathrm{~h}$ our measured IL-6 value was significantly higher compared with at $24 \mathrm{~h}$ measured value. Presumably the reason of this phenomenon that our mice were infected in-

Acta Microbiologica et Immunologica Hungarica 61, 2014 
travenously while Steinshamn et al. give the infected inoculum intraperitoneally to mice [18].

In our VVC mouse model, significant IL-6 level increase was not measured at $24 \mathrm{~h}$. Presumably the reason of this phenomenon that the infection remained local, therefore it could not trigger systemic immune response against $C$. albicans. By $72 \mathrm{~h}$ the fungal vaginal burden and the measured IL-6 level further increased, but the rates of increase were slower and lower compared with those in our systemic mouse model.

In conclusion our VVC model was adjusted successfully. Serum IL-6 had strong relationship with systemic C. albicans infection, while the local C. albicans infection of the vagina led to partial, prolonged and limited serum IL-6 response. Further in vivo experiments are needed to assess the role of different cytokines in the course of mucocutaneous and systemic candidiasis.

\section{Acknowledgements}

The work was supported by the TÁMOP 4.2.2.A-11/1/KONV-2012-0023 project. The project is implemented through the New Hungary Development Plan, co-financed by the European Social Fund and the European Regional Development Fund. The authors deny any conflicts of interest.

The authors thank Katalin Orosz-Tóth for inoculating mice.

\section{References}

1. Mishra, N.N., Prasad, T., Sharma, N., Payasi, A., Prasad, R., Gupta, D.K., Singh, R.: Pathogenicity and drug resistance in Candida albicans and other yeast species. A review. Acta Microbiol Immunol Hung 54, 201-235 (2007).

2. Kim, J., Sudbery, P.: Candida albicans, a major human fungal pathogen. J Microbiol 49, 171-177 (2011).

3. Pfaller, M.A., Diekema, D.J.: Epidemiology of invasive candidiasis: A persistent public health problem. Clin Microbiol Rev 20, 133-163 (2007).

4. Pfaller, M.A., Neofytos, D., Diekema, D., Azie, N., Meier-Kriesche, H.U., Quan, S.P., Horn, D.: Epidemiology and outcomes of candidemia in 3648 patients: Data from the Prospective Antifungal Therapy (PATH Alliance ${ }^{\circledR}$ ) registry, 2004-2008. Diagn Microbiol Infect Dis 74, 323-331 (2012).

5. Majoros, L., Kardos, G., Pócsi, I., Szabó, B.: Distribution and susceptibility of Candida species isolated in the Medical University of Debrecen. Acta Microbiol Immunol Hung 49, 351-361 (2002).

Acta Microbiologica et Immunologica Hungarica 61, 2014 
6. Dóczi, I., Pető, Z., Fodor, E., Bereczki, L., Nagy, E., Hajdú, E.: Evaluation of fungaemia infections in a Hungarian university hospital between 1996 and 2009. Acta Microbiol Immunol Hung 59, 29-41 (2012).

7. Yano, J., Noverr, M.C., Fidel, P.L., Jr.: Cytokines in the host response to Candida vaginitis: Identifying a role for non-classical immune mediators, S100 alarmins. Cytokine 58, 118-128 (2012).

8. Sobel, J.D.: Vulvovaginal candidosis. Lancet 369, 1961-1971 (2007).

9. Fidel, P.L., Jr.: Immunity in vaginal candidiasis. Curr Opin Infect Dis 18, 107-111 (2005).

10. Fidel, P.L., Jr., Lynch, M.E., Conaway, D.H., Tait, L., Sobel, J.D.: Mice immunized by primary vaginal Candida albicans infection develop acquired vaginal mucosal immunity. Infect Immun 63, 547-553 (1995).

11. Fidel, P.L., Jr., Cutright, J., Steele, C.: Effects of reproductive hormones on experimental vaginal candidiasis. Infect Immun 68, 651-657 (2000).

12. Wozniak, K.L., Wormley, F.L., Fidel, P.L., Jr.: Candida-specific antibodies during experimental vaginal candidiasis in mice. Infect Immun 70, 5790-5799 (2002).

13. Fidel, P.L., Jr., Wolf, N.A., Kukuruga, M.A.: T lymphocytes in the murine vaginal mucosa are phenotypically distinct from those in the periphery. Infect Immun 64, 3793-3799 (1996).

14. Földi, R., Kovács, R., Gesztelyi, R., Kardos, G., Berényi, R., Juhász, B., Szilágyi, J., Mózes, J., Majoros, L.: Comparison of in vitro and in vivo efficacy of caspofungin against Candida parapsilosis, C. orthopsilosis, C. metapsilosis and C. albicans. Mycopathologia 174, 311-318 (2012).

15. Trethon, A., Prinz, G., Varga, A., Kocsis, I.: Characteristic of nosocomial bloodstream infections at a Hungarian cardiac surgery centre. Acta Microbiol Immunol Hung 59, 271-283 (2012).

16. Romani, L., Mencacci, A., Cenci, E., Spaccapelo, R., Toniatti, C., Puccetti, P., Bistoni, F., Poli, V.: Impaired neutrophil response and CD4+ T helper cell 1 development in interleukin 6-deficient mice infected with Candida albicans. J Exp Med 183, 1345-1355 (1996).

17. Van Enckevort, F.H.J., Netea, M.G., Hermus, A.R.M.M., Sweep, C.G.J., Meis, F.G.M., Van der Meer, J.W.M., Kullberg, B.J.: Increased susceptibility to systemic candidiasis in interleukin-6 deficient mice. Med Mycol 37, 419-426 (1999).

18. Steinshamn, S., Waage, A.: Tumor necrosis factor and interleukin-6 in Candida albicans infection in normal and granulocytopenic mice. Infect Immun 60, 4003-4008 (1992). 